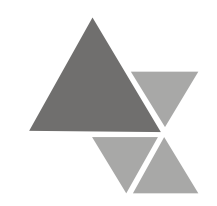

\title{
Listeria Monocytogenes em Queijo Minas Frescal e Critérios para a Avaliação de Risco
}

\author{
Rafaela Moledo de Vasconcelos ${ }^{1}$, Victor Augustus Marin ${ }^{2}$
}

Das espécies de Listeria, a Listeria monocytogenes é considerada patogênica, causando a listeriose. Surtos têm sido associados à ingestão de produtos lácteos. O objetivo deste trabalho foi descrever os critérios para avaliação de risco de L. monocytogenes em queijo minas frescal. A maior parte da literatura estudada aborda os alimentos prontos para o consumo, originados de leite e alguns de seus derivados. Por isso, foi feito um levantamento das informações necessárias para avaliação de risco em queijo minas frescal, seguindo as etapas: identificação do perigo, caracterização do perigo, avaliação da exposição e caracterização do risco. Foi verificado um escasso acervo literário sobre avaliação de risco de L. monocytogenes em queijo minas frescal, mostrando a necessidade de um estudo mais específico com queijos provenientes de vários Estados brasileiros, por este ser um tema de importância para a saúde pública.

Palavras-chaves: Listeria monocytogenes, listeriose, avaliação de risco, queijo minas frescal.

\section{Listeria Monocytogenes in Minas Frescal Cheese and Criteria for Risk Assessment}

Among the species of Listeria, the L. monocytogenes is considered pathogenic and responsible for listeriosis. Outbreaks have been associated with the ingestion of milk products. The aim of this work was to describe the criteria for risk assessment of L. monocytogenes in Minas Frescal cheese. Most of literature surveyed approaches ready-to-eat foods and some dairy products. Therefore, it was deemed of interest for the consumer to survey the most pertinent available information for risk assessment of this typical Brazilian cheese, Minas Frescal, with particular focus on the following stages: hazard identification, hazard characterization, exposure assessment and risk characterization. Little information was found in the literature about risk assessment for L. monocytogenes in Frescal cheese, showing the need for a detailed study about cheeses from the various Brazilian states for this is an important issue concerning public health.

Keywords: Listeria monocytogenes, listeriosis, risk assessment, frescal cheese.

\footnotetext{
${ }^{1}$ Instituto Nacional de Controle de Qualidade em Saúde (INCQS) - Fundação Oswaldo Cruz (FIOCRUZ)

${ }^{2}$ Bolsista FAPERJ/FIOCRUZ - INCQS/FIOCRUZ.
} 


\section{Introdução}

O gênero Listeria é constituído por seis espécies: L. monocytogenes, L. seeligeri, $L$. ivanovii, L. innocua, $L$. welshimeri, $L$. grayi. Somente duas espécies são consideradas patogênicas: L. monocytogenes em humanos e L. ivanovii em outros mamíferos. Algumas pesquisas indicam que L.seeligeri e L. ivanovii causam doenças em humanos [1]. De acordo com Koneman et al. [2], existe uma espécie chamada de $L$. denitrificans, que não está associada a doenças humanas. Entretanto, no estudo de Silva et al. (1997) apud Polegato [3], a espécie $L$. denitrificans foi reclassificada no novo gênero Jonesia (J. denitrificans).

Segundo o Bacterial Analytical Manual (BAM) da FDA/CFSAN [4], Doumith et al. [5] e Nelson et al. [6], há 13 sorovares da L. monocytogenes: $1 / 2 \mathrm{a}, 1 / 2 \mathrm{~b}, 1 / 2 \mathrm{c}, 3 \mathrm{a}, 3 \mathrm{~b}, 3 \mathrm{c}$, $4 \mathrm{a}, 4 \mathrm{~b}, 4 \mathrm{c}, 4 \mathrm{~d}, 4 \mathrm{e}, 4 \mathrm{ab}$ e 7. Porém, para Borucki \& Call [7], há 14 sorotipos de $L$. monocytogenes descritos.

De acordo com Drevets, Leenen e Greenfield [8]; Gasanov, Hughes e Hansbro [1] e Borucki et al. [9], os sorotipos 1/2a, 1/2b e $4 \mathrm{~b}$ de $L$. monocytogenes são comumente implicados em casos de listeriose humana. Entre as cepas recuperadas de alimentos, o sorotipo 1/2a é o mais representado [6].

A listeriose permanece como um significante problema para a saúde pública. A comparação entre os tipos de cepas de $L$. monocytogenes que causam surtos é importante, pois define a sobrevivência, o crescimento e a patogenicidade de cada um [6].

\section{Contaminação em queijo}

Nos Estados Unidos, há aproximadamente 76 milhões de casos de doenças derivadas de alimentos, com 32.500 hospitalizações e 5.000 mortes a cada ano. Cerca de $90 \%$ dos casos de listeriose resultam em hospitalização. De 1996-1997, foram reportados 2.493 casos de listeriose, com 499 mortes [10].
Na França, de 1999-2003, houve em média 230 casos de listeriose/ano, com 38 casos de mortes de adultos/ano e 18 casos de mortes de neonatos e fetos/ano. O sorotipo mais comumente encontrado foi o $4 \mathrm{~b}$ [11] .

Os relatórios anuais de vários países sobre as doenças derivadas de alimentos indicam que o leite e derivados são implicados em 1-5\% de surtos bacterianos. De 1983-1999, 10 surtos derivados de L. monocytogenes foram identificados: 2 associados com leite pasteurizado, 2 com manteiga, 6 com queijo, onde 3 foram fabricados com leite cru. Em 1985, houve mais de 140 casos de mortes devido a um tipo de queijo produzido com leite pasteurizado [12].

$\mathrm{O}$ consumo de produtos derivados de leite na União Européia é substancial, com média de $132 \mathrm{Kg} /$ pessoa anualmente. O leite e derivados são consumidos por grupos de todas as idades. Os derivados do leite têm sido associados a aproximadamente metade dos casos de surtos de listeriose reportados na Europa [13].

Segundo Catão \& Ceballos [14], existem vários registros da presença de $L$. monocytogenes em leite e derivados. A frequiência dos casos de listeriose veiculados por queijos evidencia a importância desse alimento e outros derivados do leite na cadeia epidemiológica de transmissão de Listeria spp. Diversos surtos de doenças graves têm sido associados à ingestão de produtos lácteos, em razão principalmente da presença de $L$. monocytogenes [15].

Os problemas com a produção de queijo no Brasil estão relacionados às péssimas condições do leite produzido, às condições de fabricação dos queijos e à falta ou à ineficiência do sistema de refrigeração ao longo da cadeia produtiva, que agravam a situação e criam condições de contaminação e desenvolvimento de microrganismos [15]. A qualidade e durabilidade de um produto dependem, em grande parte, da matéria-prima utilizada na sua fabricação. É difícil melhorar a qualidade de um produto, se o número de microrganismos inicialmente presente no leite "in natura" é elevado [18]. Para produção 
segura de queijos recomenda-se usar leite pasteurizado para reduzir os riscos à saúde pública [17].

A presença de microrganismos patogênicos nos alimentos é resultante de uma interação de fatores que envolvem o patógeno em si e o alimento que o veiculará, podendo atuar amplificando ou atenuando a contaminação e os níveis de multiplicação destes microrganismos. Entre estes fatores, pode-se citar o processamento, a distribuição, o consumo e a imunidade da população. Assim, para garantir segurança microbiológica dos alimentos, deve-se atuar em todas as fases, minimizando os níveis iniciais de contaminação, prevenindo ou limitando o potencial de multiplicação e eliminando os microrganismos indesejáveis [18].

Há uma preocupação com a qualidade higiênico-sanitária dos queijos, devido à diversidade de produtos existentes e pela importância que eles têm em hábitos da população saudável e na nutrição de crianças, grávidas, idosos e pessoas doentes, que, direta ou indiretamente, possuem o sistema imunológico enfraquecido [16].

Análises realizadas pelo Inmetro [19] em queijo minas frescal e padrão de vários Estados do Brasil, divulgadas em abril de 2006, revelaram não- conformidade, pois $33 \%$ das marcas que tiveram amostras analisadas não atenderam aos padrões da legislação, ou seja, apresentaram contaminação com bactérias potencialmente patogênicas. Uma das marcas analisadas (5\%), proveniente do Estado de São Paulo, mostrou contaminação por L. monocytogenes.

Um estudo de Silva, Hofer e Tibana (1998) constatou alta incidência $(41,17 \%)$ de L. monocytogenes em queijo minas frescal artesanal [20]. De acordo com Institute of Food Technologists - IFT [21], um queijo estilo mexicano causou 142 casos da doença em 1984 e 12 casos de 2000-2001. A mortalidade foi de $33,8 \%$ e $41,7 \%$, respectivamente.

Alta incidência de L. monocytogenes foi detectada em queijos de massas mole e semimole, feitos com leite cru, na Suécia. O microrganismo estava presente em níveis inferiores a $10^{2} \mathrm{UFC/g}$, na maioria dos casos [22]. Outro estudo realizado na Europa constatou a incidência desse microrganismo em queijos produzidos com leite pasteurizado (8\%) superior à encontrada em queijos produzidos com leite cru $(4,8 \%)$ [20]. Em Portugal, L. monocytogenes foi isolada em 6 das 371 amostras de queijo fabricado com leite pasteurizado e em 2 das 50 amostras de queijo fresco [23].

No trabalho de Silva et al. (1998) foi observada incidência de Listeria spp. em diferentes tipos de queijo, incluindo: minas frescal, ricota, gorgonzola, brie, cheddar, camembert e roquefort. Das 103 amostras de queijo analisadas, $11(1,68 \%)$ estavam contaminadas por L. monocytogenes, 13 $(12,62 \%)$ por $L$. innocua, $6(5,83 \%)$ por $L$. grayi e $1(0,97 \%)$ por $L$. welshimeri. A maior incidência de $L$. monocytogenes foi observada em queijo minas frescal caseiro, seguida por queijos maturados (gorgonzola, brie e roquefort) e minas frescal e ricota industrialmente elaborados [16].

Considerando a necessidade de aperfeiçoamento das ações de controle sanitário na área de alimentos, visando a proteção da saúde da população e a qualidade microbiológica dos produtos alimentícios, a Resolução - RDC no 12 , de 02/01/2001, da Agência Nacional de Vigilância Sanitária ANVISA, estabelece ausência de $L$. monocytogenes em $25 \mathrm{~g}$ de amostra como padrão microbiológico sanitário para queijo de umidade muito alta, como o queijo minas frescal [24].

Apesar da importância da ocorrência de L. monocytogenes em produtos láticos, existem somente algumas pesquisas sobre sua incidência nesses alimentos no Brasil [20]. Por isso, são interessantes novos estudos sobre este microrganismo patogênico em queijos [14].

\section{Análise de Risco / Avaliação de Risco}

O órgão americano Food and Drug Administration's Center for Food Safety and 
Applied Nutrition (FDA/CFSAN), em colaboração com United States Department of Agriculture's Food Safety and Inspection Service (FSIS), Centers for Disease Control and Prevention (CDC), Food and Agriculture Organization of the United Nations (FAO) e World Health Organization (WHO), em 2003, propôs a avaliação da estimativa de risco relativo de doença ou morte associada ao consumo de diferentes tipos de alimentos prontos que foram contaminados por $L$. monocytogenes [25].

A combinação da propagação de $L$. monocytogenes com alta taxa de mortalidade faz com que esse patógeno seja um importante tópico para análise de risco. Diferentes estudos têm sido feitos considerando vários aspectos da análise de risco, como incidência e avaliação de exposição ou relação doseresposta, baseada em estudos com ratos, ou baseados em informações epidemiológicas [26].

O conceito de avaliação de risco microbiológico (Microbiological Risk Assessment - MRA) surgiu quando a Organização Mundial de Comércio (OMC) estabeleceu o Acordo Sanitário e Fitosanitário, conhecido internacionalmente como WTO/SPS Agreement (World Trade Organization/Sanitary and Phytosanitary Agreement) [27]. Este acordo especifica que a segurança de um alimento para consumo humano e sua adequação para o comércio internacional devem estar baseadas em dados científicos e em uma avaliação de risco. $\mathrm{O}$ WTO/SPS Agreement baseia-se no Codex Alimentarius para definir o que é segurança de um alimento e para especificar como a análise de risco e, particularmente, a avaliação de risco devem ser realizadas, uma vez que o Codex Alimentarius é o organismo internacional para a regulamentação e definição das exigências de qualidade e segurança (inocuidade) de alimentos [28].

A avaliação de risco provém uma estrutura organizada de informações, para melhor entender a interação entre os microrganismos, alimentos e doenças humanas. Provém habilidade de estimar o risco à saúde humana, decorrente de microrganismos em alimentos, e é usada no gerenciamento de risco relacionado a patógenos de alimentos e na elaboração de padrões para alimentos no comércio internacional [29]. A decisão é aceitar o risco e informar ao consumidor ou implementar ações para redução do risco a níveis toleráveis [28].

De acordo com a Resolução $n^{\circ} 17$, de 30/04/1999, da ANVISA, foi aprovado o Regulamento Técnico que estabelece as Diretrizes Básicas para a Avaliação de Risco e Segurança dos Alimentos. Surgiu devido ao consenso científico sobre a relação existente entre alimentação-saúde-doença e vem despertando, em todo o mundo, o interesse no uso dos alimentos como um dos determinantes importantes da qualidade de vida; novos conceitos relativos às necessidades de nutrientes em estados fisiológicos especiais e à possibilidade de efeitos benéficos significativos de outros compostos, nãonutrientes, dos alimentos; aumento da expectativa de vida, fatores ligados à urbanização, à influência da mídia e aos aspectos econômicos ligados à industrialização de novos alimentos; inovações tecnológicas, a globalização da economia, a intensificação da importação de alimentos e a necessidade da harmonização da legislação em nível internacional e possibilidade de que novos alimentos ou ingredientes possam conter componentes, nutrientes ou não-nutrientes com ação biológica, em quantidades que causem efeitos adversos à saúde [30].

De acordo com McLauchlin et al. [31], avaliação de risco é definida como um processo científico para determinar a relação entre a exposição a um determinado perigo e as condições que podem causar um efeito adverso à saúde. Segundo a Resolução no 17 , de 30/04/1999, da ANVISA, perigo é o agente biológico, químico ou físico, ou propriedade de um alimento, capaz de provocar um efeito nocivo à saúde; risco é a função da probabilidade de ocorrência de um efeito adverso à saúde e da gravidade de tal efeito, 
como consequiência de um perigo ou perigos nos alimentos. A avaliação de risco é definida como o processo fundamentado em conhecimentos científicos, envolvendo as fases: identificação do perigo, caracterização do perigo, avaliação da exposição e caracterização do risco. Na identificação do perigo há a determinação dos agentes biológicos, químicos e físicos que podem causar efeitos adversos à saúde e que podem estar presentes em certo alimento ou grupo de alimentos. A caracterização do perigo é uma avaliação qualitativa e/ou quantitativa da natureza dos efeitos adversos à saúde, associados com agentes biológicos, químicos e físicos que podem estar presentes nos alimentos. A avaliação da exposição é considerada também uma avaliação qualitativa e/ou quantitativa da ingestão provável de agentes biológicos, químicos e físicos através dos alimentos, assim como as exposições que derivam de outras fontes, caso sejam relevantes. E por fim, a caracterização do risco é definida como estimativa qualitativa e/ou quantitativa, incluídas as incertezas inerentes, da probabilidade de ocorrência de um efeito adverso, conhecido ou potencial, e da gravidade para a saúde de uma determinada população, com base na identificação do perigo, sua caracterização e a avaliação da exposição [30].

De acordo com o Codex Alimentarius, a Avaliação de Risco (Risk Assessment) é um dos componentes da Análise de Risco (Risk Analysis), que é formada por mais dois itens: Gestão de Risco (Risk Management) e Comunicação de Risco (Risk Communication) [32].

Segundo World Health Organization/ Food and Agriculture Organization [25], para avaliação de risco da $L$. monocytogenes, algumas questões devem ser relacionadas: estimativa de risco da doença desse patógeno em alimento, quando se classifica ausência em $25 \mathrm{~g}$ de alimento; estimativa de risco da doença para consumidores de diferentes grupos de populações suscetíveis relativos a uma população geral e estimativa de risco da doença desse microrganismo em alimentos que suportem ou não seu crescimento em armazenamento específico e em condições de vida de prateleira. É preciso responder estas questões, a fim de avaliar como interagem os fatores relacionados à doença oriunda de alimentos e desenvolver estratégias para reduzir as taxas de doença.

Para que o controle da multiplicação bacteriana em alimentos ocorra de forma ideal, é preciso uma sistemática compilação de dados relativos ao comportamento e fisiologia dos microrganismos [33]. Alimentos sempre representarão algum risco biológico, porém a indústria de alimentos possui como meta manter esse nível de risco em taxas mínimas, garantindo a saúde do consumidor [18].

No estudo de Gray et al. [34], foram obtidos resultados que suportam a existência de diferenças entre a virulência e transmissibilidade entre os subtipos de $L$. monocytogenes. Entendendo a variabilidade das cepas encontradas em humanos, alimentos, animais, ambiente e as características da virulência expressadas por diferentes cepas, contribui-se para a melhora da avaliação do risco à saúde pública devido à L. monocytogenes.

O administrador do risco é quem seleciona o perigo. $\mathrm{O}$ avaliador do risco descreve o comportamento e outras características importantes do perigo selecionado e determina o nível de exposição ao perigo, analisando os produtos ou descrevendo a rota completa dos materiais crus, transporte, processamento e estoque para o consumo. É chamado de Dynamic Flow Tree model, Process Risk Model, Pathogen-Product pathway ou Farm-to-Fork model. Isto permite estimar vários níveis de perigo em várias circunstâncias e a probabilidade da população ser exposta. Por fim, o avaliador do risco combina a informação de exposição com a relação dose-resposta e a severidade dos efeitos e então avalia o risco (Caracterização do Risco). É estimada a probabilidade e a severidade da doença devido a um patógeno particular, num alimento particular e num grupo específico de consumidores [28].

Somente alguns dos riscos estimados 
pelos avaliadores são objetivo de gerenciamento pelo governo. A estimativa do risco é feita uma vez, e depois os gerentes de risco do governo decidem se as medidas de controle são necessárias, quais opções disponíveis e as medidas de controle para impedir ou reduzir a doença derivada do alimento [28].

O objetivo deste trabalho foi descrever os critérios para avaliação de risco de $L$. monocytogenes em queijo minas frescal, visto que este alimento é de grande consumo da população brasileira.

\section{Critérios para Avaliação de Risco}

\section{Identificação do Perigo}

\begin{abstract}
$\mathrm{Na}$ identificação do perigo, realiza-se o levantamento dos efeitos à saúde relacionados à L. monocytogenes, determinando as características do patógeno e estabelecendo uma relação entre ele e a presença no alimento, verificando casos de doença e/ou morte associados com o consumo de alimentos contaminados [35].
\end{abstract}

\section{Histórico}

De acordo com WHO/FAO [29], estudos demostram que $L$. monocytogenes pode ter sido isolada de pacientes na Alemanha em 1891. Murray, Webb e Swann (1926) isolaram uma pequena bactéria grampositiva que tinha causado doença em 1924 em coelhos e porcos da Índia. Eles nomearam o organismo de Bacterium monocytogenes. Pirie, em 1927, isolou e descreveu o mesmo organismo de fígado de roedores na África, nomeando a bactéria de Listerella hepatolytica. Em 1940, o nome foi alterado para Listeria monocytogenes. $\mathrm{O} 1^{\circ}$ trabalho de listeriose humana foi em 1929 e o $1^{\circ}$ caso perinatal em 1933 [29].

$\mathrm{O}$ microrganismo tem sido reportado por causar doença em animais domésticos e selvagens e tem sido isolado em numerosas espécies de mamíferos, pássaros, anfíbios, peixes, crustáceos, insetos e répteis, como também de solo, poeira, água, esgoto, vegetais e silagem. Entretanto, o primeiro caso de listeriose derivada de alimento não foi reportado até 1953 , quando o nascimento de gêmeos mortos foi associado ao consumo de leite cru, pela mãe, proveniente de uma vaca com mastite, causada por Listeria [29].

\section{Características da L. monocytogenes}

L. monocytogenes é uma bactéria gram-positiva, não esporulada, que expressa motilidade a $20-25^{\circ} \mathrm{C}$, mas não a $35^{\circ} \mathrm{C}$. É psicotrófica e cresce em faixa de temperatura de $0-45^{\circ} \mathrm{C}$, com temperatura ótima de $37^{\circ} \mathrm{C}$. Pode crescer em níveis de $\mathrm{pH}$ entre 4.4 e 9.4 e em índices de atividade de água acima ou igual a 0.92 [29]. De acordo com Lake et al. [36], esse patógeno pode permanecer ativo durante um longo tempo em ambientes secos, possuindo habilidade para crescer em temperatura de refrigeração $\left(4^{\circ} \mathrm{C}\right)$ e seu $\mathrm{pH}$ ótimo é 7.0. A bactéria cresce muito bem em condições microaerófilas, assim como aerobicamente e anaerobicamente, sendo rapidamente inativada a $70^{\circ} \mathrm{C}$ e $\mathrm{pH}$ menores que 4.4.

\section{Descrição do grupo de alimento}

Na década de 90, a produção total brasileira de leite evoluiu a uma taxa média de $4,3 \%$ ao ano. Com o crescimento da produção de leite sob inspeção federal, cresceu também a produção de leite clandestino. A produção informal de produtos lácteos brasileiros cresceu $50 \%$ e a formal apenas $16 \%$. Com isso, aumenta o consumo de produtos clandestinos, indicando que a população brasileira está cada vez mais consumindo produtos de baixa qualidade, que podem comprometer sua saúde [37].

A elaboração de queijos é uma das mais importantes atividades das indústrias de laticínios, sobretudo no Brasil, onde o queijo minas frescal é um dos tipos mais consumidos [38].

$$
\text { De acordo com a Associação }
$$


Brasileira de Indústrias de Queijo (ABIQ), o Brasil produz 400 mil toneladas de queijo por ano [15]. Em um estudo realizado no ano 2000, o queijo minas frescal apareceu entre os três queijos mais produzidos, estando atrás somente dos queijos mussarela e prato [39]. Sua massa possui alto teor de umidade (46$55 \%$ ), é crua e recomenda-se seu consumo até 15 dias após a fabricação [40]. Queijos frescos, brancos e leves, que são submetidos a um processamento mínimo antes de serem embalados, são altamente perecíveis e, por isso, apresentam vida útil curta, mesmo sob refrigeração [15].

\section{Listeriose}

L. monocytogenes pode causar listeriose invasiva por penetrar no trato gastrointestinal e estabelecer infecções em sítios normalmente estéreis dentro do corpo, uma vez que esta bactéria penetra no tecido intestinal e atinge células do sistema imune, os fagócitos. Dentro deles, ela é capaz de escapar do fagossomo e crescer [25].
Este microrganismo possui habilidade de infectar e crescer intracelularmente em células mamárias in vitro, incluindo enterócitos, macrófagos, hepatócitos, neurônios e fibroblastos. L. monocytogenes, $L$. ivanovii e $L$. seeligeri mostram propriedades de invasão e difusão que outras espécies de Listeria não possuem [31].

Os sintomas da listeriose são: febre alta, tremores, dor de cabeça grave, rigidez no pescoço e náusea. A listeriose em grávidas pode provocar aborto e nascimento prematuro. Se o infectado for do grupo de risco, dentro de dois meses apresentará febre e os primeiros sinais de doença. A maioria dos lactentes infectados torna-se gravemente doente, podendo apresentar abscessos disseminados em órgãos como cérebro, pulmões, fígado, baço, rins, ossos, pele e tecidos moles [29].

A União Européia fez um estudo, em 2001, relatando o número de casos de listeriose em vários países, conforme Tabela 1 :

Tabela 1. Número de casos de listeriose humanaem diversos países de 1999 a 2001

\begin{tabular}{cccc}
\hline País & $\mathbf{1 9 9 9}$ & $\mathbf{2 0 0 0}$ & $\mathbf{2 0 0 1}$ \\
\hline Bélgica & 64 & 48 & 57 \\
\hline Dinamarca & 44 & 39 & 38 \\
\hline Finlândia & 46 & 18 & 28 \\
\hline França & 275 & 261 & 187 \\
\hline Alemanha & 31 & 33 & 213 \\
\hline Espanha & 32 & 35 & 67 \\
\hline Suíça & 27 & 46 & 136
\end{tabular}

Fonte: European Union [41]

\section{Exposição do problema e escopo para avaliação de risco}

Segundo a WHO/FAO [29], três pontos específicos devem ser considerados para a avaliação do risco de listeriose derivada de alimento:

- Estimar o risco da doença de $L$. monocytogenes no alimento, quando o número de organismos variam de ausentes em $25 \mathrm{~g}$ a 
1.000 Unidades Formadoras de Colônias (UFC) por grama ou mililitro ou não exceda os níveis especificados no ato do consumo;

- Estimar o risco da doença para consumidores de diferentes grupos de populações susceptíveis (idosos, bebês, mulheres grávidas e pacientes imunocomprometidos) com relação a população geral, e

- Estimar o risco da doença de $L$. monocytogenes em alimentos que suportam seu crescimento e em alimentos que não suportam seu crescimento em condições específicas de estocagem e prateleira.

\section{Caracterização do Perigo}

Na caracterização do perigo, estima-se a relação entre o nível de exposição (dose) e a frequiência de doença severa e mortalidade. Deve-se levantar informações sobre a virulência do patógeno, susceptibilidade do hospedeiro, além de traçar o modelo de avaliação dose-resposta, curvas de doseresposta para três subpopulações [35].

Segundo WHO/FAO [29], alimentos contaminados são considerados a principal rota de transmissão de listeriose e é estimado que sejam responsáveis por $99 \%$ dos casos de doença.

Há dois tipos de doença causada por L. monocytogenes: invasiva e não-invasiva. A doença invasiva, chamada de listeriose, normalmente ocorre em indivíduos com sistema imune fraco. A doença não-invasiva é usualmente chamada de gastroenterite febril, com sintomas tipo resfriado, e pode ocorrer em pessoas saudáveis que consumam um grande número de células desta bactéria [36].

A listeriose invasiva é caracterizada por disseminação da bactéria pelo sistema nervoso central e unidade fetoplacental, devido a capacidade dela cruzar a barreira intestinal, barreira sangue-cérebro e barreira feto-placenta. A L. monocytogenes caracteriza-se por produzir listeriolisina, enzima capaz de lisar as células vermelhas sanguíneas, que está associada à habilidade dessa bactéria causar doença [29].

A infecção patogênica por $L$. monocytogenes pode afetar indivíduos predispostos através de doenças que afetam o sistema imunológico, como câncer ou AIDS, e também outros indivíduos susceptíveis como idosos, mulheres grávidas, recém-nascidos ou fetos [1]. A população alvo da doença também pode ser aquela menos freqüentemente reportada, como os diabéticos, cirróticos, asmáticos e pacientes com colite ulcerativa [42], doentes renais, pacientes que fazem diálise contínua e aqueles que realizaram transplante de órgãos renal ou de medula óssea [2]. Os imunocomprometidos que também podem ser afetados são aqueles induzidos por tratamento médico com corticosteróides [21]. Outro parâmetro que é relevante para susceptibilidade do indivíduo à doença é o nível reduzido da acidez gástrica. $\mathrm{O}$ uso de antiácido tem sido considerado fator de risco para listeriose [29].

Na maioria dos casos, os sintomas são diarréia, febre, dor de cabeça e mialgia e, em alguns, gastroenterite. No caso de listeriose sistêmica em mulheres não-grávidas, pode ocorrer infecção do sistema nervoso, com ou sem bacteremia. Manifestações menos comuns são peritonite, hepatite e abcesso hepático, endocardite, infecção arterial, miocardite, infecção pulmonar e líquido pleural, osteomielite e artrite séptica e úlcera córnea. Em mulheres grávidas, as manifestações são febre, resfriado e dor de cabeça. A mulher grávida pode adquirir listeriose em qualquer mês de gravidez, mas a maioria dos casos são reportados no terceiro trimestre. No primeiro trimestre, pode haver aborto espontâneo. Nos últimos estágios da gravidez, pode haver nascimento prematuro ou um recém-nato doente [29].

A severidade de um perigo pode ser classificada de forma qualitativa, semiquantitativa e quantitativa. Alguns critérios são utilizados para classificar a severidade: número de casos de doença aguda, número de mortes, número de casos de doença crônica, danos à sociedade em termos de custos médicos e perda de produtividade [29].

Estudos laboratoriais e epidemiológicos indicam que cepas de $L$. 
monocytogenes têm habilidade diferente de causar doenças. Essa variabilidade influencia o número de organismos requeridos para produzir doença e a severidade dos sintomas [35]. A resposta da população à exposição ao patógeno é variável, devido às características de virulência do patógeno, número de células ingeridas, estado de saúde e sistema imune do hospedeiro [29].

A L. monocytogenes é susceptível a vários antibióticos, mas a penicilina $\mathrm{e}$ ampicilina, opcionalmente com aminoglicosídeo (ex: gentamicina), são consideradas as melhores escolhas [36].

\section{Período de incubação}

Período de incubação da listeriose é de 1 - 90 dias. Os sintomas incluem aqueles parecidos com resfriado (ex: febre, dor de cabeça), diarréia e vômito. Em casos perinatais, pode haver septicemia, morte intrauterina, nascimento prematuro e natimortos. Em casos não-perinatais, os sintomas mais comumente associados são bacteremia e meningite [36].

Já o período de incubação da gastroenterite febril não-invasiva é de 11 horas a 7 dias, com média de 18 horas. Os sintomas são diarréia, febre, dor muscular, dor de cabeça e, menos frequiente, cãibras abdominais e vômitos [36].

\section{Informação de dose-resposta microrganismo em humanos}

De acordo com Lake et al. [36], a probabilidade de causar uma listeriose invasiva com níveis moderados de células é muito baixo. A avaliação de risco da FAO/WHO usa o modelo de dose-resposta:

$$
\mathrm{P}=1-\exp ^{-\mathrm{R}^{*} \mathrm{~N}}
$$

onde $\mathrm{P}$ é a probabilidade da doença associada à cada célula consumida, $\mathrm{R}$ é a variável que define a relação dose-resposta e $\mathrm{N}$ é o número de células consumidas. $\mathrm{O}$ valor de $\mathrm{R}$ varia dependendo do grupo de população (reflete susceptibilidades diferentes), mas está em torno de $10^{-12}-10^{-14}$. Não existe diferença de risco se um pequeno número de células for ingerida frequientemente ou se várias células forem ingeridas ao mesmo tempo, pois o total ingerido será o mesmo.

A relação dose-resposta compreende três componentes maiores, com suas incertezas: ambiente (matriz alimentar), patógeno (virulência) e hospedeiro (susceptibilidade e status imune). A matriz alimentar deve afetar a susceptibilidade da infecção, incluindo a habilidade do patógeno de sobreviver na acidez gástrica [31].

\section{Avaliação da Exposição}

A avaliação da exposição descreve a forma como o patógeno é introduzido, distribuído e ingerido com o alimento. $\mathrm{O}$ resultado desejado é a prevalência, concentração e, se possível, a virulência do patógeno no alimento quando é ingerido, além do nível de consumo da população de interesse. Em alguns casos, é necessário estimar a freqüência de contaminação de alimentos e o número total de patógenos ingerido [29]. Avalia-se a frequiência dos vários níveis de contaminação, durante $o$ tempo de venda, o impacto do manuseio do alimento e as condições de armazenamento sobre a exposição potencial. Assim será possível construir modelos de níveis do microrganismo no alimento, crescimento microbiológico entre a venda e o consumo, inativação térmica e L. monocytogenes presente no alimento para o consumo [35].

Para L. monocytogenes geralmente é necessário descrever a prevalência e a concentração desse patógeno em ingredientes ou, especificamente, produtos finais de interesse ou ambos, descrever a quantidade de produto ingerido e a frequiência e, se possível, as características de consumo da população susceptível e avaliar a cadeia de produção do alimento. A prevalência e concentração dessa bactéria em alimentos pode ser alterada como resultado de contaminação inicial e subsequiente, processo físico, crescimento ou inativação no produto [29].

$$
\text { A taxa de crescimento da } L \text {. }
$$


monocytogenes é afetada pela temperatura, atmosfera de armazenamento, atividade de água, $\mathrm{pH}$, presença de ácidos orgânicos, preservativos como nitrito e sorbato, presença de altos níveis de outros microrganismos de outras cepas ou espécies [29].

De acordo com Miconnet [43], para avaliação do risco microbiológico quantitativo, estima-se o risco associado a produtos contaminados com microrganismos patogênicos, sendo necessárias algumas variáveis quantitativas. Uma delas, que é introduzida nesta etapa de avaliação da exposição, é a prevalência ou proporção de unidades contaminadas. A prevalência é estimada de análises independentes de unidades amostrais (n). A probabilidade associada com a proporção desconhecida é constante, podendo ser usado o modelo binomial:

$$
\mathrm{K} \longrightarrow \operatorname{Binomial}(n, p)
$$

onde $\mathrm{K}$ é a variável aleatória associada ao número de casos positivos, $n$ é o tamanho da amostra analisada e $p$ é a probabilidade de contaminação ou infecção.

Para uma análise de risco, são necessários dados confiáveis sobre o perigo potencial associado com o alimento e as formas de controle do processo em todas as etapas da cadeia, desde a produção primária até o consumo final [18]. Outras informações como dados epidemiológicos sobre a ocorrência de doenças de origem alimentar, severidade, custos e dificuldades clínicas de tratamento [32] também são necessárias.

Como estes dados são difíceis de serem obtidos, utilizam-se modelos matemáticos e simulações para estimar os riscos, baseando-se na carga microbiana inicial em um alimento, na redução dessa carga em decorrência do processamento industrial e nas condições de armazenamento, desde o processamento até o consumo final [33]. Quando também não se conhece estes dados, utiliza-se a probabilidade, considerando a pior possibilidade. Na simulação de Monte Carlo, estes dados são combinados, permitindo calcular a probabilidade de ocorrência de uma enfermidade, causada por um determinado alimento, em uma certa população [28]. No estudo de Buchanan et al. (1997) apud Nero [18], é utilizado esse modelo para calcular a probabilidade de ocorrência de uma infecção por $L$. monocytogenes em função do número de células ingeridas, em uma população formada por adultos saudáveis.

$\mathrm{Na}$ avaliação de exposição, as propriedades de crescimento de $L$. monocytogenes são usadas para estimar o crescimento das células, durante 0 armazenamento do produto, e para quantificar o número final de células presentes no alimento no momento do consumo. Para esta avaliação, os dados sobre as propriedades de crescimento podem ser baseados em testes para crescimento de L. monocytogenes em condições específicas, na microbiologia preditiva e em informações retiradas da literatura [26].

\section{Caracterização do Risco}

Nesta etapa, os componentes do modelo são integrados para estimar a probabilidade de haver efeito adverso devido à exposição ao patógeno. A avaliação da exposição e a caracterização do perigo são integradas para expressar, matematicamente, a probabilidade dos efeitos adversos a um determinado grupo da população, assim como estimar, qualitativa e quantitativamente, a incerteza associada com os valores de risco. Também deve-se estimar a taxa de incerteza. A caracterização de risco inclui a interpretação dos resultados baseados nos modelos de predição [35].

Os resultados da avaliação da exposição e caracterização do perigo são combinados para estimar o número de casos por alimento e ano. Considerando a variabilidade e incerteza, associadas com a avaliação da exposição e caracterização do perigo, é necessário estabelecer e interpretar o risco relativo de uma categoria de alimento, que cause listeriose, com outras categorias [35]. 
Para Lake et al. [36], são necessárias informações sobre o número de casos de efeitos adversos à saúde, resultantes da exposição ao microrganismo, com referência particular ao alimento (baseado em informações da fiscalização), para traçar o risco qualitativo estimado, incluindo a categorização do nível de risco associado com o microrganismo no alimento.

De acordo com a Anvisa [44], quando se trata de segurança alimentar, aborda-se o controle de qualidade em todas as etapas de produção: o manejo e alimentação dos animais produtores, coleta e transporte da matériaprima, beneficiamento/processamento na usina e/ou indústria de laticínios, condições de estocagem e venda dos produtos no comércio, até estar disponível ao consumidor. Um sistema de rastreabilidade dos alimentos destinados ao consumo humano e dos seus ingredientes certamente contribui para proteção da saúde dos consumidores.

Quando o perigo é identificado e o risco caracterizado, trabalha-se no gerenciamento dessa informação, através de Programas de Inspeção de Indústrias de Alimentos, Programas de Monitoramento de Produtos no Comércio, alterações na legislação, elaboração de novos regulamentos técnicos, interdição de estabelecimentos produtores, cancelamento de registro do produto, proibição de fabricação, importação, distribuição e comercialização de produtos, em caso de risco iminente à saúde (em caráter transitório ou permanente) ou outras medidas que se fizerem necessárias. Em qualquer momento pode ocorrer a comunicação do risco, podendo haver um alerta à população (comunicado na mídia, advertência no rótulo de produtos, elaboração de material informativo) ou um alerta sanitário (para o público interno e externo) [44].

\section{Considerações Finais}

Devido ao escasso acervo literário sobre o tema, há necessidade de um estudo detalhado sobre avaliação de risco de $L$. monocytogenes em queijo minas frescal, proveniente de vários Estados brasileiros. Portanto, é necessário levantar informações sobre o consumo de queijo, casos de listeriose, hospitalizações e mortes, existência de surtos no Brasil e determinar a severidade e a incidência de listeriose provenientes de queijo.

Com o que foi demonstrado no decorrer deste trabalho, conclui-se que o assunto é de extrema importância no âmbito da saúde pública e deve ser de interesse governamental, assim como de toda a população, a redução e/ou eliminação do número de casos de listeriose, derivado do consumo de queijo minas frescal no Brasil.

\section{Referência Bibliográfica}

[1] Gasanov U, Hughes D, Hansbro PM. Methods for isolation and identification of Listeria spp. and Listeria monocytogenes: a review. FEMS Microbiol Rev. 2005; 29(5), 851-75.

[2] Koneman EW, Allen SD, Janda WM, Schreckenberger PC. Diagnóstico Microbiológico - Texto e Atlas Colorido. $5^{\mathrm{a}}$ ed. RJ/SP/MG: Medsi, 2001.

[3] Polegato EPS. Métodos para Diagnóstico de Listeria sp. em Alimentos. Disciplina de Ciência e Tecnologia da Carne - Curso de Pós-Graduação em Medicina Veterinária Departamento de Gestão e Tecnologia Agroindustrial - Faculdade de Medicina Veterinária e Zootecnia - UNESP. 2005. [Acesso em: 10 mai 2006]. Disponível em: http://www.dgta.fca.unesp.br.

[4] FDA/CFSAN - Food and Drug Administration / Center for Food Safety \& Applied Nutrition. Bacterial Analytical Manual (Online). Detection and Enumeration of Listeria monocytogenes in Foods. Chapter 10. Jan 2003. [Acesso em: 29 out 2005]. Disponível em: http://www.cfsan.fda.gov.

[5] Doumith M, Buchrieser C, Glaser P, Jaquet C, Martin P. Differentiation of the Major Listeria monocytogenes Serovars by Multiplex PCR. J Clin Microbiol. 2004; 42:(8), 3819-22. 
[6] Nelson K, Fouts DE, Mongodin EF, Ravel J, DeBoy RT, Kolonay JF, et al. Whole genome comparisons of serotype $4 \mathrm{~b}$ and $1 / 2 \mathrm{a}$ strains of the food borne pathogen Listeria monocytogenes reveal new insights into the core genome components of this species. Nucleic Acids Res. 2004; 32:(8), 2386-95. [Acesso em: 15 fev 2006]. Disponível em: http://www.ncbi.nlm.nih.gov.

[7] Borucki MK, Call DR. Listeria monocytogenes Serotype Identification by PCR. J Clin Microbiol. 2003; 41:(12), 553740.

[8] Drevets DA, Leenen PJM, Greenfield RA. Invasion of the Central Nervous System by Intracellular Bacteria. Clin Microbiol Rev. 2004; 17:(2), 323-47.

[9] Borucki MK, Reynolds J, Call DR, Ward TJ, Page B, Kadushin, J. Suspension Microarray with Dendrimer Signal Amplification Allows Direct and HighThroughput Subtyping of Listeria monocytogenes from Genomic DNA. J Clin Microbiol. 2005:3255-3259. [Acesso em: 15 fev 2006]. Disponível em: http://www.ncbi.nlm.nih.gov.

[10] Mead PS, Slutsker L, Dietz V, McCaig LF, Bresee JS, Shapiro C et al. Food-Related Illness and Death in the United States. Emerg Infec Dis. 1999; 5:(5), 607-25. [Acesso em: 29 jan 2008]. Disponível em: http://www.questia.com.

[11] Goulet V, Jacquet C, Martin P, Vaillant V, Laurent E, De Valk H. Surveillance of human listeriosis in France, 2001-2003. Euro Surveill. 2006; 11:(6), 79-81. [Acesso em: 29 jan 2008]. Disponível em: http://www.eurosurveillance.org.

[12] De Buyser ML, Dufour B, Maire M, Lafarge V. Implication of milk and milk products in food-borne diseases in France and in different industrialised countries. Int J Food Microbiol. 2001; 17:1-17. [Acesso em: 29 jan 2008]. Disponível em: http://www.sciencedirect.com.

[13] Lundén J, Tolvanen R, Korkeala $\mathrm{H}$. Human Listeriosis Outbreaks Linked to Dairy Products in Europe. J Dairy Sci. 2004; 87:(E. Suppl), E6-E11. [Acesso em: 29 jan 2008].
Disponível em: http://www.dairy-science.org. [14] Catão RMR, Ceballos BSO. Listeria spp., coliformes totais e fecais e E.coli no leite cru e pasteurizado de uma indústria de laticínios no Estado da Paraíba (Brasil). Cien Tecn Alim. 2001; 21:(3), 281-7.

[15] Lisita MO. Evolução da população bacteriana na linha de produção do queijo minas frescal em uma indústria de laticínios. [dissertação]. Piracicaba (SP): Universidade de São Paulo (USP); 2005. [Acesso em: 05 fev 2006]. Disponível em: http://www.teses.usp.br.

[16] Olivieri DA. Avaliação da qualidade microbiológica de amostras de mercado de queijo mussarela, elaborada a partir de queijo de búfala (Bubalus bubalis). [dissertação]. Piracicaba (SP): Universidade de São Paulo (USP); 2004. [Acesso em: 12 fev 2006]. Disponível em: http://www.teses.usp.br.

[17] Leite RL. Avaliação da qualidade microbiológica de queijo "Minas frescal" e "Minas padrão" elaborados com leite proveniente de vacas com mastite subclínica. [dissertação]. Lavras: Universidade Federal de Lavras; 2000.

[18] Nero LA. Listeria monocytogenes e Salmonella spp. em leite cru produzido em quatro regiões leiteiras no Brasil: ocorrência e fatores que interferem na sua detecção. [tese]. São Paulo: Universidade de São Paulo (USP); 2005. [Acesso em: 12 fev 2006]. Disponível em: http://www.teses.usp.br.

[19] INMETRO. Análise de queijo minas frescal provenientes de vários Estados brasileiros. 2006. [Acesso em: 28 out 2006]. Disponível em: http:www.inmetro.gov.br.

[20] Feitosa T, Borges MF, Nassu RT, Azevedo EHF, Muniz CR. Pesquisa de Salmonella sp., Listeria sp. e microrganismos indicadores higiênico-sanitários em queijos produzidos no Estado do Rio Grande do Norte. Cien Tecn Alim. 2003; 23 :(supl), 1625.

[21] IFT - Institute of Food Technologist S. Society for Food Science and Technology. Scientific Status Summary. Bacteria Associated with Foodborne Diseases. 2004.

[22] Loncarevic S, Danielsson-Tham ML, 
Tham W. Occurrence of Listeria monocytogenes in soft and semi-soft cheeses in retail outlets in Sweden. Int $\mathrm{J}$ Food Microbiol. 1995; 26:245-250.

[23] Mena C, Almeida G, Carneiro L, Teixeira P, Hoog T, Gibbs PA. Incidence of Listeria monocytogenes in different food products commercialized in Portugal. Food Microbiol. 2004:213-6.

[24] Brasil. RDC $N^{o} 12$, de 2 de janeiro de 2001. Aprova o Regulamento Técnico sobre Padrões Microbiológicos para Alimentos. Diário Oficial da República Federativa do Brasil, Brasília, DF, 10 jan. 2001. [Acesso em: 20 out 2005]. Disponível em: http://elegis.bvs.br.

[25] WHO/FAO - World Health Organization / Food and Agriculture Organization. Risk assessment of Listeria monocytogenes in ready-to-eat foods: interpretative summary. Microbiological risk assessment series; 2004a: (4). [Acesso em: 19 out 2005]. Disponível em: http://www.fao.org/es/esn.

[26] Francois K, Devlieghere F, Uyttendaele M, Debevere J. Risk Assessment of Listeria monocytogenes: Impact of Individual Cell Variability on the Exposure Assessment Step. Risk Anal. 2006; 26:105-14. [Acesso em: 3 set 2006]. Disponível em: http://www.blackwellsynergy.com.

[27] ICMSF - International Commission on Microbiological Specifications for Foods, Microorganisms in foods 7: Microbiological testing in food safety management. Kluwer Academic/Plenum Publishers, 2002.

[28] Reij MW, Schothorst MV. Critical Notes on Microbiological Risk Assessment of Food. Braz J Microbiol. 2000; 31: 01-08. [Acesso em: 2 set 2006]. Disponível em: http://www.scielo.com.br.

[29] WHO/FAO - World Health Organization / Food and Agriculture Organization. Risk assessment of Listeria monocytogenes in ready-to-eat foods: technical report. Microbiological risk assessment series. 2004b:(5). [Acesso em: 05 fev 2006]. Disponível em: http://www.fao.org/es/esn.

[30] Brasil. Resolução $\mathrm{n}^{\circ}$ 17, de 30 de abril de 1999. Aprova o Regulamento Técnico que estabelece as Diretrizes Básicas para a Avaliação de RISCO e Segurança dos Alimentos. Diário Oficial da República Federativa do Brasil, Brasília, DF, 03 mai 1999. [Acesso em: 19 set 2006]. Disponível em: http://e-legis.bvs.br.

[31] McLauchlin J, Mitchell RT, Smerdon WJ, Jewel K. Listeria monocytogenes and listeriosis: a review of hazard characterization for use in microbiological risk assessment of foods. Int J Food Microbiol. 2004; 92:15-33. [32] WHO/FAO - World Health Organization / Food and Agriculture Organization. Report of the Joint FAO/WHO: Expert Consultation on Risk Assessment of Microbiological Hazards in Foods. Rome. 2000:17-21.

[33] McMeekin TA, Brown J, Krist K, Miles D, Neumeyer K, Nichols DS, et al. Quantitative microbiology: a basis for food safety. Emerg Infec Dis. 1997; 3:(4), 541-9.

[34] Gray M, Zadoks RN, Fortes ED, Dogan $\mathrm{B}$, Cai S, Chen $\mathrm{Y}$, et al. Listeria monocytogenes Isolates from Foods and Humans Form Distinct but Overlapping Populations. Appl Environ Microbiol. 2004:5833-41. [Acesso em: 15 fev 2006]. Disponível em: http://www.ncbi.nlm.nih.gov.

[35] FDA/CFSAN; USDA/FSIS; CDC. Quantitative Assessment of Relative Risk to Public Health from Foodborne Listeria monocytogenes Among Selected Categories of Ready-to-Eat Food. F Saf. 2003. [Acesso em: 03 set 2006]. Disponível em: http://www.foodsafety.gov.

[36] Lake R, Hudson A, Cressey P, Nortje G. Risk profile: Listeria monocytogenes in processed ready-to-eat meats. Institute of Environmental Science \& Research Limited, Christchurch Science Centre. 2002. [Acesso em: 07 out 2006]. Disponível em: http://www.nzfsa.govt.nz

[37] Scalco AR. Proposição de um Modelo de Referência para Gestão da Qualidade na Cadeia de Produção de Leite e Derivados. [tese]. São Carlos: Universidade Federal de São Carlos (UFSCar); 2004. [Acesso em: 26 fev 2006]. Disponível em: http://www.bdtd.ufscar.br [38] Behmer MLA. Tecnologia do leite. 15 ed. 
São Paulo: Nobel, 1991, 320p.

[39] Omairi L. Avaliação da qualidade e identidade do queijo Minas frescal comercializado na cidade de Campinas - SP. [dissertação]. Campinas: Universidade Estadual de Campinas, 2002.

[40] Hoffman FL, Silva JV, Vinturim TM. Qualidade microbiológica de queijos tipo "Minas frescal", vendidos em feiras livres na região de São José do Rio Preto, SP. Hig Alim. 2002; 16:(96),69-76.

[41] EU - European Union. Trends and sources of zoonotic agents in the European Union and in Norway. 2001. [Acesso em: 21 out 2005]. Disponível em: http://europa.eu.int/comm/food.

[42] FDA/CFSAN - Food and Drug Administration / Center for Food Safety \& Applied Nutrition. Bad Bug Book. Foodborne Pathogenic Microorganisms and Natural Toxins Handbook. Listeria monocytogenes.
2004. [Acesso em: 23 out 2005]. Disponível em: http://www.cfsan.fda.gov.

[43] Miconnet N, Cornu M, Beaufort A, Rosso L, Denis J. Uncertainty Distribution Associated with Estimating a Proportion in Microbial Risk Assessment. Risk Anal. 2005; 25:(1),39-48. [Acesso em: 20 out 2006]. Disponível em: http//www.blackwellsynergy.com.

[44] ANVISA. Agência Nacional de Vigilância Sanitária. Ministério da Saúde. Gerência-Geral de Alimentos. Gerência de Ações de Ciência e Tecnologia de Alimentos. XIX Congresso Nacional de Laticínios; MESA REDONDA: "Segurança Alimentar na Cadeia do Leite"; TÍTULO: "Controle de Alimentos - Aplicação dos Princípios de Análise de Risco", 2002. [Acesso em: 10 mai 2006]. Disponível em: http//www.anvisa.gov.br.

\section{Autores}

Rafaela Moledo de Vasconcelos - Instituto Nacional de Controle de Qualidade em Saúde (INCQS) Fundação Oswaldo Cruz (FIOCRUZ) - Programa de Pós-Graduação em Vigilância Sanitária.

Correspondência: Avenida Brasil 4365, Manguinhos, CEP: 21045-900, Rio de Janeiro - RJ. Telefone/Fax: (21) 3865-5139. E-mail: rafamoledo@ gmail.com

Victor Augustus Marin - Instituto Nacional de Controle de Qualidade em Saúde (INCQS) - Fundação Oswaldo Cruz (FIOCRUZ) - Departamento de Microbiologia e Programa de Pós-Graduação em Vigilância Sanitária.

Recebido em: 01/10/2007

Aceito em: 17/06/2008 